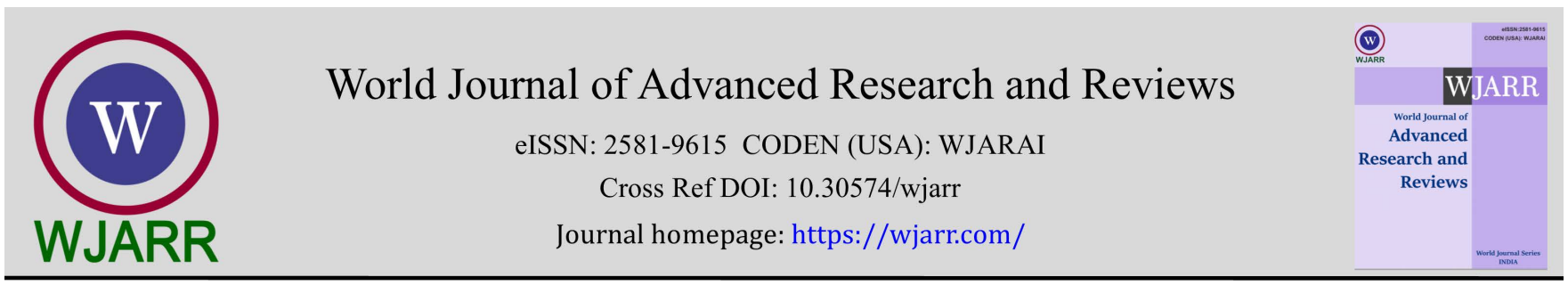

(RESEARCH ARTICLE)

Check for updates

\title{
Varietal screening of Solanaceae accessions against $R$. solanacearum strains, agent of bacterial wilt in Côte d'Ivoire
}

\author{
Mohamed Doumbouya 1, Anderson Mohamed Yeo 2, Carine Aya N'Guessan 1, ${ }^{*}$, Arthur Martin Affery ${ }^{2}$ and \\ Daouda Koné 3,4 \\ ${ }^{1}$ Department of plant Biology, Biological Training and Research Unity, Péléforo Gon Coulibaly University, BP 1328 \\ Korhogo, Côte d'Ivoire. \\ ${ }^{2}$ Faculty of Agronomic, Forestry and Environmental Engineerin, Man University, BP 20 Man, Côte d'Ivoire. \\ ${ }^{3}$ Plant Physiology Laboratory, Biosciences Training and Research Unity, Félix Houphouët-Boigny University, 22 BP 582 \\ Abidjan 22, Côte d'Ivoire. \\ ${ }^{4}$ Center of Excellence on Climate Change, Biodiversity and Sustainable Agriculture.
}

World Journal of Advanced Research and Reviews, 2021, 11(02), 313-320

Publication history: Received on 13 July 2021; revised on 24 August 2021; accepted on 26 August 2021

Article DOI: https://doi.org/10.30574/wjarr.2021.11.2.0384

\begin{abstract}
Bacterial wilt caused by $R$. solanacearum is a constraint that limits the production of solanaceous in Côte d'Ivoire. The genetic control, which is more widely used, comes up against the genetic and phenotypic variability of the strains. The objective of this study was to screen commercial and traditional varieties of Solanaceae against Ivorian strains of different phylotypes to assess their spectrum of resistance to the disease. The level of virulence of the five strains of $R$. solanacearum was evaluated in semi-controlled conditions against eight varieties of Solanaceae (pepper, eggplant and tomato). Four groups of strains were identified according to the level of virulence. Group 4, composed of strains (RUN 1794 and RUN 1854) of phylotype III and I, respectively, and originating from the localities of Kondoukro and Yamoussoukro, was very virulent. The resistant varieties were for the F1 kalenda eggplant, for the yellow chilli from Burkina and for the F1 Lindo tomato. These varieties could be used in the fight against bacterial wilt in Côte d'Ivoire.
\end{abstract}

Keywords: Screening; Solanaceae; wilt; Ralstonia solanacearum; Côte d'Ivoire

\section{Introduction}

Market gardening has long occupied a negligible proportion in farm households in the industrial crop [1]. However, with the fall in the costs of raw materials, it increasingly integrates agricultural systems, and is practiced in all production areas [2]. Market gardening occupies an important place in the agricultural sector and is considered a food sovereignty activity [3]. Market gardening provides producers with a substantial income and constitutes an incomegenerating activity allowing them to meet some basic needs [4]. It is made up of different crops including tomato (Solanum lycopersicum), pepper (Capsicum spp.), eggplant (Solanum melongena), etc. These crops (tomato, pepper, eggplant) are among the 40 most common vegetable species. most produced in the world [5]. These vegetables are used almost in all Ivorian dishes [6]. However, their production is plagued by many abiotic and biotic constraints, in particular bacterial wilt. Bacterial wilt caused by $R$. solanacearum causes considerable damage and is listed as one of the major phytosanitary problems in the world [7]. Bacterial wilt caused by Ralstonia solanacearum is rife all over the world, mainly in the tropics and $[8,9]$. In Côte d'Ivoire, it was observed for the first time in 1984 in plots of eggplant in Adiopodoumé [10] and is now found almost in all production areas with a pest which has caused the abandonment of

\footnotetext{
${ }^{*}$ Corresponding author: Carine Aya N'Guessan

Départment of plant Biology, Biological Training and Research Unity, Péléforo Gon Coulibaly University, BP 1328 Korhogo, Côte d'Ivoire.
}

Copyright (c) 2021 Author(s) retain the copyright of this article. This article is published under the terms of the Creative Commons Attribution Liscense 4.0. 
certain market gardening plots. In addition, the work of N'Guessan et al. (2012) [11] allowed to know the existing variability of strains in Côte d'Ivoire. Despite the many studies undertaken for a long time, bacterial wilt remains a very destructive disease and the means of control remain very insufficient. The extreme diversity (pathological, ecological, biochemical, genetic) strains of $R$. solanacearum make the control of this disease very difficult [12]. To control this disease, methods based on prophylactic methods, chemical control and genetic control are employed. However, the exploitation of varietal resistance including varietal control is considered the most appropriate even if some strains of $R$. solanacearum find ways to resist. Lasting resistance to a disease has become a trait of major agronomic interest that opposes the evolutionary capacity of pathogens [12]. This is the framework for our work, which has the general objective of finding strategies for combating bacterial wilt by screening a range of varieties of different nightshades.

\subsection{Plant material}

The plant material used consisted of different varieties of Solanaceae. These varieties of Solanaceae are composed of 4 varieties of tomato (Tropimech [TRO], Lindo [LIN], F1Thorgal [THOR] and a traditional variety [TDIt]), 2 varieties of pepper (Burkina yellow [JB] and a traditional [TDIp]) and 2 varieties of eggplant (N'drowa Issia [NDRO] and F1Kalenda $[\mathrm{KA}])$. The traditional varieties come from Korhogo and the other varieties were bought from Semivoire.

\subsection{Bacterial strains}

Five strains of $R$. solanacearum (Table 1) were used. These strains belong to three phylotypes described in Côte d'Ivoire (N'Guessan et al., 2012) [11] and isolated on different hosts.

\subsection{Setting up the nursery}

The test was carried out at the National Floristic Center of Félix Houphouët-Boigny University. For the nursery, eight cells at the rate of one cell per variety were used to build the nursery. The seedlings were carried out in the pockets containing potting soil. The cells were stored in a greenhouse. The seedlings were watered regularly until the plants were 4 weeks old.

Table 1 Strains used for inoculation

\begin{tabular}{|l|l|l|l|l|}
\hline Strains & Phylotypes & Séquevars & Origin & Isolation host \\
\hline RUN 1743 & phylotype I & 31 & Daloa & Eggplant \\
\hline RUN 1744 & phylotype I & 31 & Man & Eggplant \\
\hline RUN 1753 & phylotype II & 35 & Sinfra & Tomato \\
\hline RUN 1794 & phylotype III & 48 & Kondoukro & Eggplant \\
\hline RUN 1854 & phylotype I & 14 & Yamoussoukro & Tomato \\
\hline
\end{tabular}

\subsection{Experimental apparatus}

After 4 weeks in the nursery, the plants were transplanted at the six-leaf stage into pots. The experimental set-up used was Fisher's block with full randomization. The device consists of 06 blocks separated by $0.5 \mathrm{~m}$ including 05 blocks for the stumps and 01 block for the control (Figure 1). 


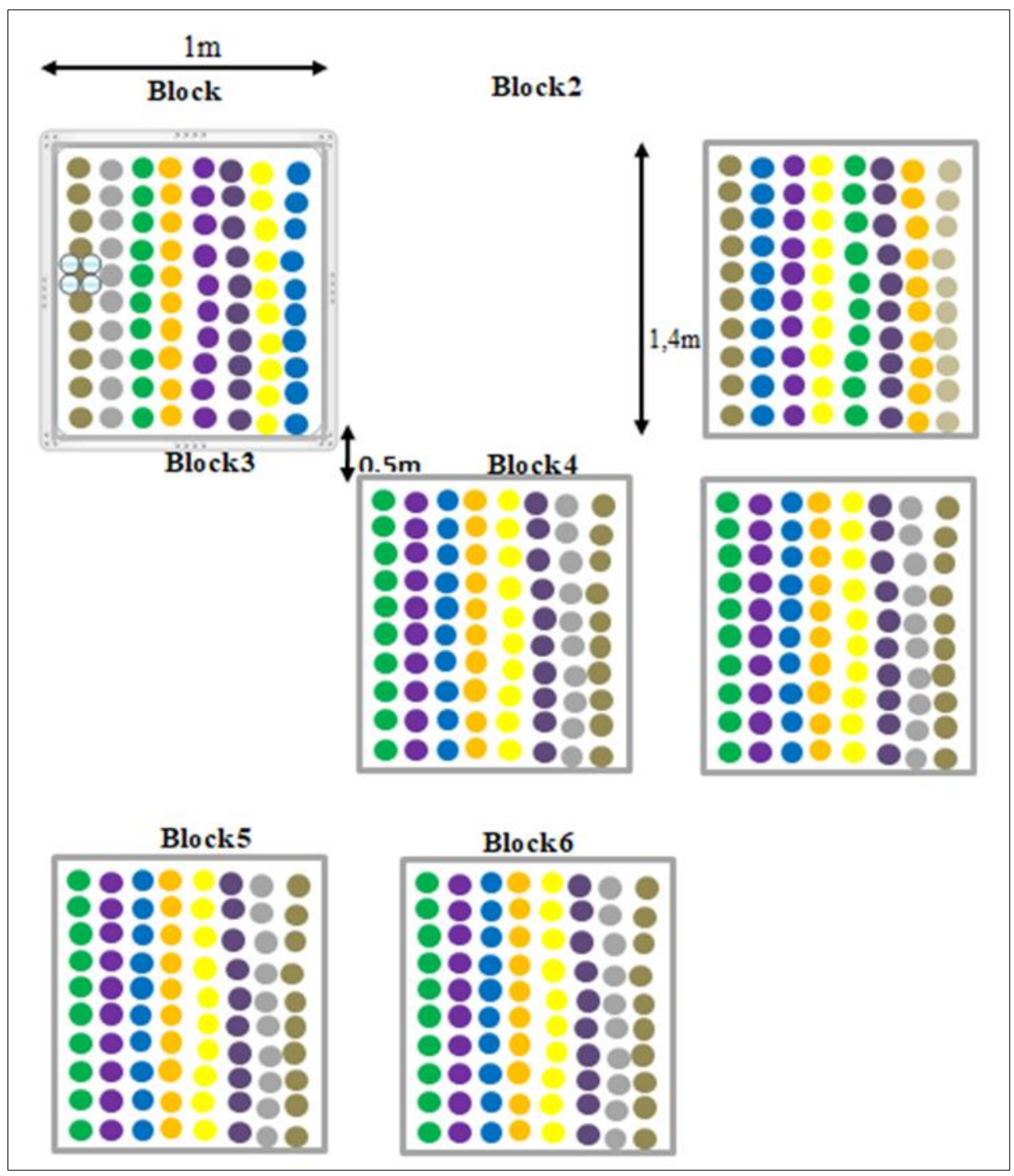

Figure 1 Experimental apparatus
: Kalenda, : N’drowa Issia,
: Tropimèch,
: Thorgal,
: Lindo,
: Traditonal tomato,
: Taditional pepper, : Burkina Yellow (JB)

\subsection{Virulence / aggressiveness test}

The bacterial wilt resistance test was carried out in a greenhouse with a temperature between 26.7 and $30{ }^{\circ} \mathrm{C}$.

The bacterial strains, in lyophilized form, were suspended in nutrient broth for 48 hours in an oven at a temperature of $28{ }^{\circ} \mathrm{C}$. Bacterial colonies in the nutrient broth were then seeded onto CPG medium [13]. After inoculation, the Petri dishes were incubated in an oven at a temperature of $28^{\circ} \mathrm{C}$. After three days of incubation, the colonies of Ralstonia solanacearum were purified on new culture media to obtain colonies typical of $R$. solanacearum. Bacterial inoculum was prepared from 24 hour old bacterial colonies and then calibrated to a concentration of $10^{8} \mathrm{CFU} / \mathrm{mL}$. The inoculation was done 7 days after transplanting the plants.

The roots of the plants were scarified with a scalpel. Then, a volume of $5 \mathrm{ml}$ of bacterial suspension was spread at the foot of each plant. Each "strain x variety" combination had ten plants.

Symptoms were monitored from the third day after inoculation for 28 days. Symptoms were assessed every two days according to the following rating scale [14]:

0: No symptoms

1: a withered leaf 
2: two or three withered leaves;

3: all withered leaves;

4: bent or dead stem of the plant.

At the end of the test, isolation on the tomato stalks was carried out on the asymptomatic plants in order to verify the presence or not of $R$. solanacearum. $2-3 \mathrm{~cm}$ sections of the stem of each plant were made at the root collar followed by alcohol disinfection. These sections are transferred to $5 \mathrm{~mL}$ of distilled water and left for 2 hours at room temperature to promote the release of bacterial colonies in distilled water. A volume of $50 \mu \mathrm{L}$ of each extract was inoculated on SMSA medium. The Petri dishes were then incubated at $28^{\circ} \mathrm{C}$ for $3-4$ days. Asymptomatic plants were noted positive for latent infection when characteristic colonies of $R$. solanacaerum were observed. Data obtained from latent infections were used to calculate the colonization index (CI).

Different parameters were calculated after 28 days of observation:

- $\quad$ The wilting index (IF) reflects the incidence of the disease, taking into account notes 3 and 4.

$$
\mathrm{IF}=\frac{\mathrm{N} 3+\mathrm{N} 4}{\mathrm{~N}} \times 100
$$

IF: Wilting index; Number of plants with a score of 3: Number of plants with note 4; N: Total number of plants observed.

- The colonization index (CI) (Prior et al., 1996) [15] determined from latent infections.

$$
\mathrm{IC}=\mathrm{IF}+(\mathrm{NS} X \mathrm{RS})
$$

NS:Percentage of asymptomatic plants; RS: percentage of asymptomatic plants with latent infection.

\subsection{Statistical analyzes}

Data analysis was performed with R software version 4.0.2 (R Core Team, 2020) [16]. In this analysis, the working definitions proposed by Lebeau et al. (2011) [17] and [2] were included in this study.

The phenotypic groups were defined as groups of strains showing similarities in virulence on the 8 accessions studied.

Analyzes of the interactions of Solanaceae accessions/bacterial strains by considering the index of wilting and colonization made it possible to identify the bacteria / plant interaction classes on the basis of the reference phenotypes [17].

Based on the final wilt and colonization indices, each strain-accession combination was assigned to a phenotypic class from the reference phenotypes. This assignment is made using the "k nearest neighbor" (knn) algorithm. available in the class R software package.

From the phenotypes observed on the 8 accessions, an ascending hierarchical classification was made with the agnes function of the library cluster using the Ward's aggregation index to classify the strains of bacteria into homogeneous groups. Then, the number of phenotypic groups was determined based on the distance between the nodes of the dendrogram and the phenotypic data.

\section{Results}

\subsection{Classification of bacterial strains of $R$. solanacearum according to their level of virulence and aggressiveness}

Analysis of the dendrogram based on final wilt and colonization indices at an aggregation height of about 2.6 distinguished four groups of bacterial strains (Figure 2). 


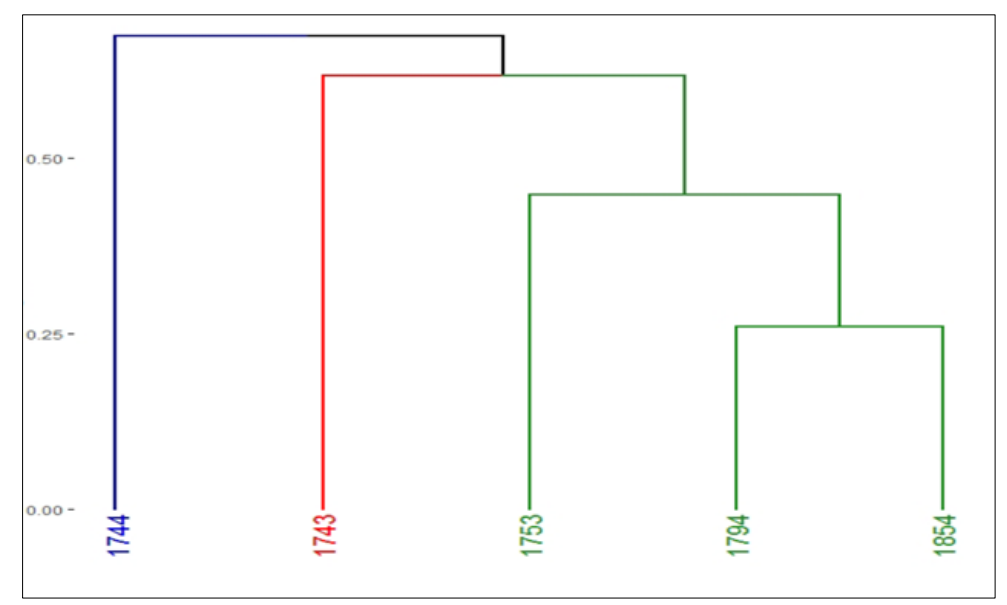

Figure 2 Tree of ascending hierarchical classification of 5 Ivorian strains of $R$. solanacearum (agglomerative coefficient $=0.36$ )

- Group 1 includes the strain (RUN 1744) from Man of phylotype I. It is characterized by a very low virulence on all 8 accessions of Solanaceae and only affects varieties of tomato (LIN), eggplant (N'DRO), and chilli pepper (TDIp).

- Group 2 is composed of the strain (RUN1743) from Daloa of phylotype I which is characterized by medium virulence affecting varieties of eggplant (KA), tomato (LIN TDIt, THOR), pepper (TDIp).

- Group 3 comprises the strain (RUN1753) of phylotype II from Sinfra. It is characterized by high virulence on N'DRO eggplant and TDIp pepper varieties, but moderately on other varieties of nightshades.

- Group 4 comprises two strains (RUN 1854 and 1794) of phylotype I and III respectively. It is characterized by a very high level of virulence on all varieties with the exception of the JB pepper and KA eggplant varieties.

\subsection{Classification of varieties according to their level of resistance to the different strains of $R$. Solanacearum}

The resistance levels and spectra were found to vary according to the accessions. The cultivar dendrogram (Figure 3 ) is subdivided into three groups which are distinguished by their degree of resistance to the different strains of the phytobacterium R. solanacearum.

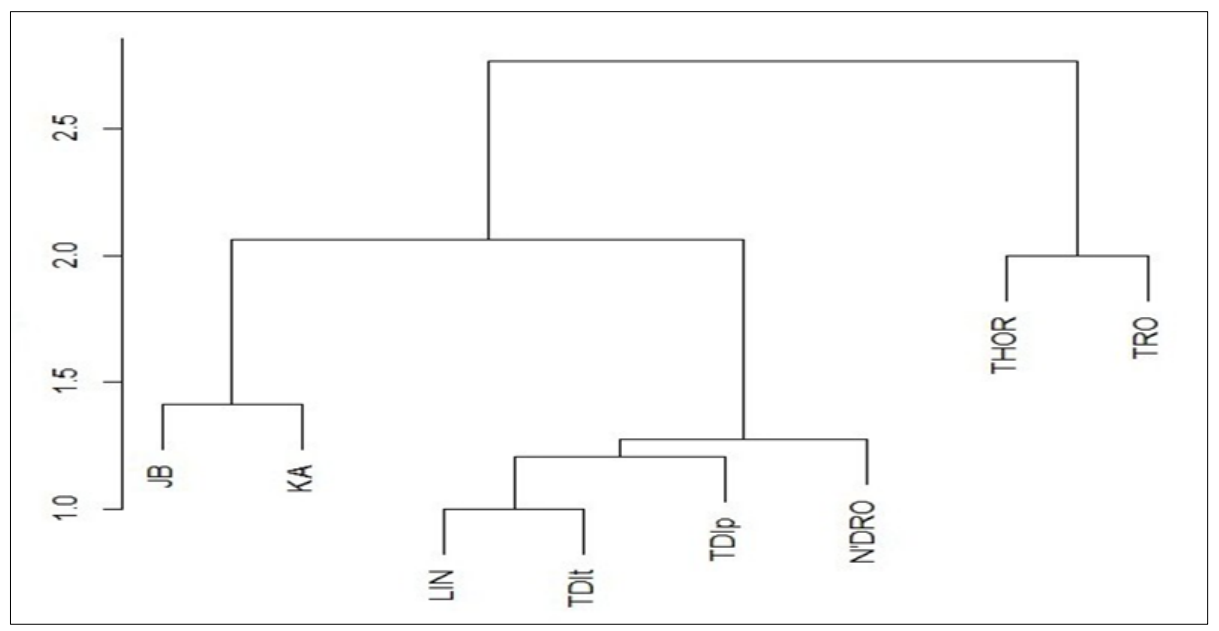

Figure 3 Tree of ascending hierarchical classification of 8 accessions of $R$. Solanaceae (agglomerative coefficient = 0.49)

- Group 1, made up of varieties of yellow Burkina pepper and F1kalenda eggplant, were very resistant to different strains of $R$. solanacearum.

(Graph) 
- Group 2 includes 4 varieties including Lindo tomato (Lin) and traditional tomato (TDIt), traditional pepper (TDIp), and eggplant N'drowa Issia (N'DRO) have been shown to be moderately resistant to different strains of $R$. solanacearum.

- Group 3 consists of the following two varieties of tomato Thorgal (THOR) and Tropimech (TRO) which have been shown to be very sensitive to the different strains of $R$. solanacearum.

\subsection{Phenotypic interaction between Solanaceae accessions and $R$. solanacearum strains}

The levels and spectrum of resistance were found to be variable depending on the variety and the strain (Table 2). The tomato varieties (TRO, THOR, LIN, TDIt) were shown to be sensitive to the strains of $R$. solanacearum tested with the exception of the strains (RUN 1743 and 1744).

- In eggplant, the variety KA and N'DRO have been shown to be resistant to the strains. However, N'DRO was susceptible to strain RUN 1794 phylotype III.

- The varieties of peppers have been shown to be resistant or tolerant to the strains with the exception of the traditional pepper which has been shown to be sensitive to the RUN 1854 strain of Yamoussoukro.

- Also the analysis of the results shows a strong virulence of these three strains (RUN 1854, 1753 and 1794) on all accessions except chilli pepper (JB), and eggplant (KA) which were very resistant.

Table 2 Phenotypic interaction between the 8 accessions of Solanaceae and the strains tested

\begin{tabular}{|c|c|c|c|c|c|c|}
\hline Varieties & Strains (RUN) & 1743 & 1744 & 1753 & 1794 & 1854 \\
\hline \multirow{2}{*}{ Pepper } & JB & 1 & 2 & 2 & 1 & 2 \\
\hline & TDIp & 2 & 2 & 2 & 1 & 4 \\
\hline \multirow{2}{*}{ Eggplant } & KA & 2 & 1 & 1 & 1 & 1 \\
\hline & N'DRO & 2 & 1 & 2 & 4 & 2 \\
\hline \multirow{4}{*}{ Tomato } & LIN & 2 & 1 & 2 & 4 & 4 \\
\hline & TDIt & 3.2 & 2 & 3.1 & 4 & 4 \\
\hline & THOR & 1 & 2 & 4 & 4 & 4 \\
\hline & TRO & 2 & 1 & 3.1 & 5 & 5 \\
\hline
\end{tabular}

\section{Discussion}

This study made it possible to screen varieties of Solanaceae against different strains and to assess the level of virulence of strains from different localities in Côte d'Ivoire.

Among the speculations used, it is necessary to know that the tomato is the speculation most attacked by all strains of the phytobacterium. The tomato plants wilted following inoculation with $R$. solanacearum because they were very sensitive to all inocula. This would mean that the tomato plants do not have very effective defense mechanisms to be able to control or limit the actions of $R$. solanacearum in the soil. According to studies conducted by Koffi et al. (2019) [18] on 279 tomato accessions, two (2) were found to be moderately resistant and only 4 showed high resistance to bacterial wilt caused by $R$. solanacearum.

The Lindo variety (Lin) was shown to be not very sensitive to the strains on the whole but against the RUN 1794 strain and the RUN 1854 strain where it was moderately sensitive while the Tropimech (TRO) and F1 Thorgal (THOR) varieties were very sensitive to the 5 strains. These results may be due to the fact that the behavior or reaction of a strain depends on the variety to which it is competed and that there are varieties which do not exhibit tolerance levels towards the strain R. solanacearum.

These results corroborate with that of N'Guessan et al. (2012) [11] who showed that there are different levels of susceptibility to bacterial wilt in tomatoes, ranging from highly sensitive to the most resistant varieties by carrying out studies on the characterization of strains of $R$. solanacearum in Côte d'Ivoire. 
However, the eggplant and chilli varieties were less susceptible to different strains of $R$. solanacearum. But, among these, the variety "F1kalenda" and the yellow variety from Burkina showed a strong resistance in semi-controlled condition to all the strains tested and even influenced the level of infectious inoculum studied. The eggplant (KA) and chilli (JB) varieties are said to carry a primordial resistance gene among so many other varieties. In addition, these two varieties would produce their own repellent or antibacterial compounds at the level of their root system, which would have the capacity to totally reduce or limit the composition of the flora of $R$. solanacearum. These root elements play a primary role in the defense of plants against $R$. solanacearum. Strains, which have caused latent infection in eggplant under semicontrolled conditions, can be very virulent in the field and in the laboratory. On the other hand, it is more likely that KA and JB greatly reduced the potency of the infectious inoculum in the soil. Thus, the likelihood of the appearance of virulence properties capable of infecting and spreading throughout the plant remains minimal. These results are similar with those of Alla et al. (2019) [19] who stated that F1kalenda was very tolerant to bacterial wilt following the study of four manures on the agromorphological parameters.

\section{Conclusion}

The work carried out made it possible to assess the level of virulence of 5 strains of Ralstonia solanacearum on 8 varieties of nightshades tested. Four phenotypic groups were found. It was noted that the same variety can be resistant to strains belonging to different phylotypes. Thus, the most resistant varieties were the F1 Kalenda eggplant, Burkina yellow pepper and Lindo tomato varieties. It also appears that the three strains of $R$. solanacearum (RUN 1753, RUN 1794, RUN 1854) originating respectively from Sinfra, Kondoukro and Yamoussoukro were the most virulent with more than $50 \%$ of wilt index (IF) in most varieties. The varietal control against bacterial wilt in Solanaceae certainly requires the construction of new genotypes of Solanaceae, endowed with more lasting resistance, in particular capable of controlling a majority of the many strains that constitute the $R$. solanacearum species complex.

\section{Compliance with ethical standards}

\section{Acknowledgments}

We are also grateful to Dr Ouattara thimoté for revision, writing and data analysis of the manuscript.

\section{Disclosure of conflict of interest}

The authors declare that no competing interests exists

\section{References}

[1] Coulibaly N, Bly JP. Overview of Ivorian agriculture through data from the 2001 national agricultural census survey frame from RGPH 98. Project GCP / IVC / 025 / EC - FAO - EU. Ministry of Agriculture and Animal Resources, Côte d'Ivoire. 2002; 17.

[2] N'Guessan AC. Phylogeny, genetic structure and virulence diversity of Ralstonia solanacearum Yabuuchi et al. (1995) [Burkhloderiaceae], agent of bacterial wilt in Côte d'Ivoire. Unique Doctoral Thesis, Biosciences research and Training Unity. 2013.

[3] FA0. Growing greener cities in Africa. First status report on urban and peri-urban horticulture in Africa. Rome, Food and Agricultural Organization of the United Nations. 2012; 116.

[4] Mondjédji A, Nyamador W, Amevoin K, Adéoti R, Abbey G, Ketoh G, et Glitho I. Analysis of some aspects of the vegetable production system and producers' perception of the use of botanical extracts in the management of insect pests of vegetable crops in southern Togo. International Journal of Biological and Chemical Sciences. 2015; 9(1): 98- 107.

[5] Lebeau A, Daunay MC, Frary A, Palloix A, Wang JK., Dintinger J, Chiroleu F, Wicker E, Prior P. Bacterial wilt resistance in tomato, pepper, and eggplant: genetic resources respond to diverse strains in the Ralstonia solanacearum species complex. Phytopathology. 2011; 101: 154-165.

[6] Soro S, Doumbia M, Dao D, Tschannen A, Girardin O. Performance of six cultivars of Lycopersicon esculentum Mill tomatoes. against leaf spoon yellows, bacterial wilt and root knot nematodes. Sciences et nature. 2007; 4: 123130. 
[7] Mansfield J, Genin S, Magori S, Citovsky V, Sriariyanum M, Ronald P, Dow M, Verdier V, Beer SV, Machado MA, Tothi I, Salmond G. Foster GD. Top 10 plant pathogenic bacteria in molecular plant pathology. Molecular Plant Pathology. 2012; 13(6): 614-629.

[8] EPPO. European and Mediterranean Organization for the Protection of Plants. Bulletin. 2005; 35: 361-362.

[9] Parkinson N, Bryant R, Bew J, Conyers C, Stones R, Alcock M, Elphinstone J. Application of Variable Number Tandem Repeat (VNTR) Typing to Discriminate Ralstonia solanacearum Strains Associated with English Watercourses and Disease Outbreaks. Applied and Environmental Microbiology. 2013; 79(19): 6016-6022.

[10] Declert C. Manual of phytopathology of tropical vegetable crops. Cultures of Ivory Coast editions O.R.S.T.O.M., Paris. 1990; 333.

[11] N'Guessan CA, Abo K, Fondio L, Chiroleu F, Lebeau A, Poussier S, Wicker E, Koné D. So near and yet so far: the specific case of Ralstonia solanacearum populations from Côte-d'Ivoire in Africa. Phytopathology. 2012; 102: 733740 .

[12] Poussier S. Exploration of the genetic diversity of Ralstonia solanacearum, agent of bacterial wilt. Detection and dynamics of populations in inoculum reservoirs. Doctoral Thesis: Biology. University of Rennes .2000.

[13] Kelman A. The Relationship of Pathogenicity of Pseudomonas solanacearum to Colony Appearance in a Tetrazolium Medium. Phytopathology. 1954; 44: 693-695.

[14] Coupat-Goutaland B, Bernillon D, Guidot A, Prior P, Nesme X, Bertolla F. Ralstonia solanacearum virulence increased following large interstrain gene transfers by natural transformation. Molecular Plant-microbe Interactions. 2011; 24: 497-505.

[15] Prior P, Bart S, Leclercq S, Darasse A, Anaïs G. Resistance to bacterial wilt in tomato as discerned by spread of Pseudomonas (Burkholderia) solanacearum in the stem tissues. Plant Pathology.1996; 45: 720-7267.

[16] R Core Team. R: A language and environment for statistical computing. R Foundation for Statistical Computing, Vienna, Austria. 2020.

[17] Lebeau A. Resistance of tomato, eggplant and pepper to Ralstonia solanacearum: Interactions between resistance broodstock and bacterial diversity, characterization and mapping of genetic factors involved in eggplant. Ph.D. Faculty of Science and Technology, University of Reunion: Saint Denis de la Réunion. 2010.

[18] Koffi NBC, Yapo SES, Soro D, N'guettia YM, Ayolie KC, Atta HD. Control of bacterial wilt in tomatoes by using wild eggplant as a rootstock in Côte d'Ivoire. Revue Ivoirienne des Sciences et Technologie. 2019; 34: 178-190.

[19] ALLA KT, Bomisso EL, Ouattara G, Dick. AE. Effect of fertilization based on banana peel by-products on the agromorphological parameters of F1kalenda varieties (Solanum melongena) in the locality of Bingerville in Côte d'Ivoire. Journal of Animal \& Plant Sciences. 2018; 38(3):6292-6306. 